\title{
Recovery from large medial thalamic lesions as a result of electroconvulsive therapy ${ }^{1}$
}

\author{
C. H. VANDERWOLF \\ From the Department of Psychology, McMaster University, Hamilton, Ontario, Canada
}

\begin{abstract}
Although it is well established that electroconvulsive therapy (E.C.T.) is beneficial in the treatment of some mental disorders in man, there is little evidence of improvement in parallel states in animals. Yet, study of the effect of E.C.T. in cases of experimentally induced cerebral dysfunction in animals should be of value in elucidating its mechanism of action. The present experiment demonstrates that E.C.T. can partially restore a behavioural function which was depressed as a result of extensive medial thalamic destruction in the rat.

This experiment was attempted as a result of two lines of evidence. First, large medial thalamic lesions severely impair a rat's ability to avoid an electric shock by running away, without much affecting its ability to run after shock is applied. The animals remain motionless during avoidance training (before shock presentation), but show clear signs of fear, and special tests indicate that they can learn what to do. The impairment appears to be one of initiating the required movements, and it was suggested that the medial thalamic nuclei form part of a 'trigger' system concerned with the initiation of voluntary movement (Vanderwolf, 1962).
\end{abstract}

Secondly, there is evidence of a movementinhibiting or suppressing system which may interact with the 'trigger' system. It has been demonstrated that electrical stimulation in some areas of limbic cortex has an inhibitory effect on such motor activities as the knee-jerk and movement elicited by stimulation of the motor cortex (Kaada, 1960). Destruction of these same limbic areas results in behavioural changes suggestive of a loss of the ability to inhibit motor responses. For example, unlike normal animals, rats with septal or insular lesions or cats with lesions of the subcallosal cortex continue to drink when their water supply is electrified (McCleary, 1961; Kaada, Rasmussen, and Kveim, 1962). This does not appear to be due to a lack of sensitivity to shock.

A series of E.C.T. treatments also reduces the

${ }^{1}$ Read in part before the annual meeting of the Eastern Psychological Association, New York, 16 April, 1966. This research was supported by a grant from the National Research Council (APB-118). suppressive effects of punishment, and it may be that this too is due to dysfunction of cerebral inhibitory mechanisms (Vanderwolf, 1963). Gellhorn (1946) suggested that since E.C.T. can restore an extinguished conditioned avoidance response, its effect may be due to a disturbance of processes of Pavlovian internal inhibition. Also, the effect of E.C.T. in depressed states in man is sometimes referred to as 'disinhibition' (Holmberg, 1963).

If the response-inhibiting and response-triggering systems are in reciprocal relation, medial thalamic damage might release the response-inhibiting system. This would result in the behavioural immobility which is seen in medial thalamus-damaged rats during avoidance testing. It also follows that a treatment which reduces the activity of the responseinhibiting system should increase activity in the damaged response-triggering system, restoring it to a more nearly normal state. Therefore, E.C.T. should improve shock avoidance performance in rats with large medial thalamic lesions.

\section{EXPERIMENT 1}

METHOD

Electrolytic lesions were placed in the medial thalamic nuclei in a group of rats. Two weeks later a shock-avoidance test was administered. Animals that failed to make avoidance responses were given E.C.T. or a control treatment. ${ }^{2}$ Finally, additional avoidance training was given.

SURJECTS AND GENERAL PROCEDURE The subjects were 34 adult, male, hooded rats each weighing at least $250 \mathrm{~g}$ at the start of the experiments. All animals received bilateral electrolytic destruction of the medial part of the thalamus while under Nembutal anaesthesia. The intracranial electrode, which consisted of fine nichrome wire (insulated except for the cross-sectional area of the tip), was placed in position by means of a stereotaxic instrument. A needle inserted under the skin of the tail served as a cathodal electrode. The lesion was produced by the

2Animals that are able to avoid shock successfully are usually found to have received small or misplaced lesions. 
bilateral administration of $2 \cdot 5-3.0 \mathrm{~mA}$ anodal current which was allowed to flow for $20 \mathrm{sec}$ on each side.

After a recovery period of two weeks all animals were given 30 trials on the avoidance task described below. This was followed by a period of six to seven days during which food intake was restricted so that the animal's weight declined by $10 \%$. This was done because it has been reported that reducing body weight reduces the incidence of spinal fractures during electroconvulsive treatment (McDonald, 1960). ${ }^{3}$ The surviving animals were then divided into two groups which were approximately equated with respect to body weight, escape performance, and conditioned vocal performance. Avoidance performance was identical in the two groups since only animals with a score of zero were used.

AVOIDANCE TEST The methods used in avoidance training were similar to those described previously (Vanderwolf, 1962). The apparatus was a large box vertically divided into two compartments, each $10 \times 18 \times 18$ in. One compartment was painted black, the other white, and each had a grid floor. These compartments could be separated by a horizontally sliding door. A shock of about $1.0 \mathrm{~mA}$ could be delivered to the grid of the black compartment by means of a manually operated switch.

Training was preceded by a 5-min period of exploration during which the rat was allowed to wander about in both compartments. Following this, the rat was placed in the black compartment facing the end wall. Shock was delivered $5 \mathrm{sec}$ later. After the rat had run into the white compartment an interval of 25-30 sec was allowed before beginning the next trial. The sliding door was closed during this period to prevent re-entry to the black compartment. If the rat did not escape from the black compartment within $25 \mathrm{sec}$ after shock onset, the trial was terminated and the rat was manually placed in the white compartment. Each subsequent trial was begun by replacing the rat in the black compartment and repeating the entire procedure. An avoidance response was said to have occurred if the rat left the black compartment before shock was presented. Running from the black compartment after shock had been presented constituted escape behaviour. Records were kept of the running time (taken with a stop watch) and the occurrence of avoidance responses. The presence or absence of squealing (conditioned vocal response) during the 5 -sec period preceding shock was noted on each trial. Squealing elicited by handling was not recorded.

ELECTROSHOCK A device for producing convulsions was made by placing a resistance of $30,000 \Omega$ in series with the secondary coil of a $1500 \mathrm{~V}$ transformer. A Hunter timer in the primary circuit of the transformer limited the duration of shock to about $0.2 \mathrm{sec}$. Good contact with the rats' heads was assured by clipping saline moistened cotton packs to the two ears.

Sixteen animals received a series of 20 grand mal convulsions (spaced at intervals of $3 \mathrm{hr}$ or more) at the rate of four per day. Eighteen control rats were given

'Nonetheless, six rats received spinal injuries. Data on their performance are not presented here. a series of 'pseudo-shocks'-that is, the electrodes were clipped on but no current was delivered. During the five-day convulsive treatment the experimental animals were allowed free access to food and water, while the intake of the control animals was adjusted to keep the weights of the two groups comparable. Following completion of the E.C.T. or sham-E.C.T. treatment alt animals were allowed a recovery period of five days during which food and water were freely available.

Finally, all animals were given two days (30 trials/day of testing in the avoidance apparatus.

ANATOMICAL METHOD When testing was completed aff animals were perfused with a formalin solution while under deep barbiturate anaesthesia. The brains were removed and stored in a formalin solution for a periog of several weeks. Sections were cut at a thickness of $40 \mathbb{B}$ and stained with cresyl violet.

\section{RESULTS}

ANATOMICAL FINDINGS The thalamic lesions wer $\overrightarrow{\mathrm{g}}$ similar to those described in previous report (Vanderwolf, 1962, 1964). Four main groups of nuclei-the nuclei of the midline, the intralaminait nuclei, the medial nuclei and the habenulae-were severely damaged or absent in all cases. The anterpos thalamic nuclei and the medial hippocamol formation frequently were slightly damaged. Oceasionally, the lateral thalamic nuclei and the mediat parts of the ventral nuclei were damaged as Incidental damage of this sort is probably gow primarily responsible for the severe deficit in avegig ance performance produced by extensive mefial thalamic damage (Vanderwolf, 1962; Delacoito Albe-Fessard, and Libouban, 1966; Vanderwolpo 1967).

No differences were noted between the brains of animals that had been convulsed and those that hat not.

Figure 1 illustrates a typical medial thalami lesion.

BEHAVIOURAL FINDINGS Tables I and II give ind vidual data on avoidance, escape, and conditionez vocal responses for 34 rats which received mediat thalamic lesions followed by either E.C.T. or shams E.C.T.

Avoidance behaviour Table I shows that rats given sham-E.C.T. usually performed no better oQ the avoidance task after treatment than they had when originally tested. A 'spontaneous' improvement in performance occurred in only two rats in a grou of 18. This is not a statistically significant change. On the other hand, nine of the 16 rats that received E.C.T. improved in performance (Table II). This increase is significant $(P<0.01$; Wilcoxon test). The 


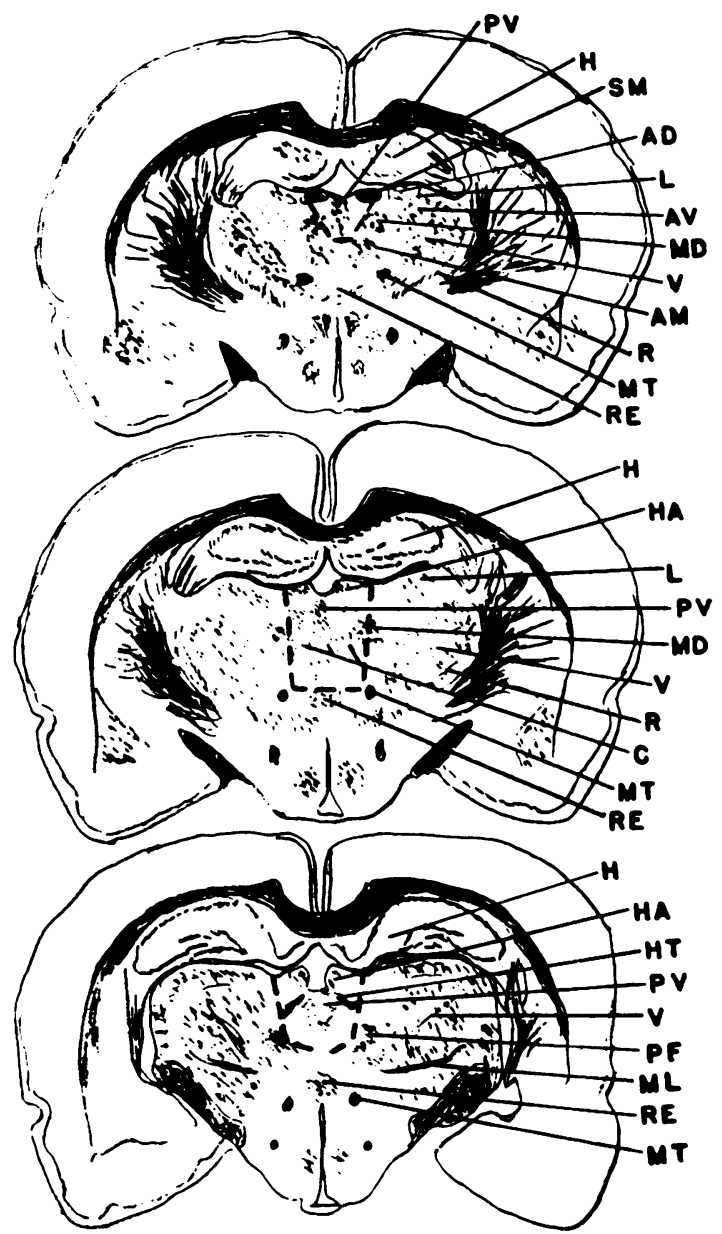

FIG. 1. Drawings of coronal sections illustrating typical medial thalamic lesions. Three sections are shown; top, anterior limit of lesion; middle, its greatest extent; bottom, posterior limit of lesion. Primary thalamic destruction is outlined by dotted line. AD, antero-dorsal nucleus; $A M$, antero-medial nucleus; $A V$, antero-ventral nucleus; $C$, centralis nuclei; $H$, hippocampus; HT, habenulo-interpeduncular tract; $L$, lateral nucleus; $M D$, medio-dorsal nucleus; $M L$, medial lemniscus; $M T$, mammillo-thalamic tract; $P F$, parafascicular nucleus; $P V$, periventricular nucleus; $R$, reticular nucleus; $R E$, reuniens nucleus; $S M$, stria medullaris; $V$, ventral nucleus.

difference between the two groups after the differential treatment is also statistically significant $(P<0.01$; Mann-Whitney test), even though performance was identical during original training.

Escape behaviour The average time taken to run out of the black compartment of the avoidance apparatus after shock was applied was usually from 1 to $3 \mathrm{sec}$ in individual animals. Thus, escape behaviour was essentially normal following medial thalamic damage, in agreement with previous findings (Cardo, 1961; Vanderwolf, 1962; Thompson, 1963; Delacour et al., 1966).

Escape performance remained relatively constant in the sham-E.C.T. treated animals but improved slightly in the convulsed group. The effect, however, is not significant statistically.

Conditioned vocal behaviour Two of the 18 rats in the sham-E.C.T. group began to develop vocal conditioned responses during the initial training session, even though they failed to avoid. During the later training sessions vocal responding became more frequent in these rats and also appeared in seven additional rats in this group. In comparison, development of vocal conditioned responses was retarded in the convulsed animals. During initial training four of these 16 rats began to develop vocal conditioned responses. The performance of these four animals did not improve during later training and none of the other convulsed animals developed vocal conditioned responses. Thus, nine of the 18 animals in the sham-E.C.T. group showed an increase in vocal performance from the initial to the final phase of training, while none of the 16 convulsed animals did so. This difference between the two groups is significant $(P<0.001$; Fisher exact probability test).

\section{EXPERIMENT 2}

Experiments by Carson (1957) and Heistad (1955) have shown that retention of learned avoidance behaviour in normal rats is impaired by a series of convulsions. Since the experiment just described demonstrated an improvement in avoidance performance following a series of convulsions in rats with medial thalamic damage, it seemed worthwhile to repeat the entire experiment with normal animals in order to confirm the earlier work.

\section{METHOD}

The procedure was identical with that of Experiment 1. A group of 18 rats was given 30 trials on the avoidance task and divided into an experimental group $(\mathrm{N}=10)$ and a control group $(\mathrm{N}=8)$. After the deprivation procedure (six days) the experimental group received a series of 20 convulsions while the control group received 20 sham treatments. Five days later both groups were given two additional days of training.

\section{RESULTS}

During initial training, the control rats received an average of 4.0 shocks in 30 trials (range $=1-9$ ) that is, they made an average of 26 avoidance 
TABLE I

AVOIDANCE, ESCAPE, AND CONDITIONED VOCAL RESPONSES IN RATS WITH MEDIAL THALAMIC LESIONS BEFORE AND AFTER SHAM-E.C.T. $(\mathbf{N}=18)$

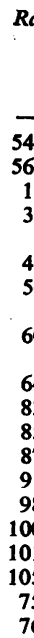

\begin{tabular}{|c|c|c|c|}
\hline \multirow{2}{*}{ Rat. No. } & \multicolumn{3}{|c|}{ After Thalamic Lesion } \\
\hline & $\begin{array}{l}\% \text { Avoidance } \\
\text { (30 trials) }\end{array}$ & $\begin{array}{l}\% \text { Vocal CR } \\
(30 \text { trials })\end{array}$ & $\begin{array}{l}\text { Escape } \\
\text { (sec) }\end{array}$ \\
\hline $\begin{array}{c}54 \mathrm{JB} \\
56 \mathrm{JB} \\
17 \\
31\end{array}$ & $\begin{array}{l}0 \\
0 \\
0 \\
0\end{array}$ & $\begin{array}{c}0 \\
0 \\
16 \cdot 7 \\
0\end{array}$ & $\begin{array}{l}3 \cdot 3 \\
2 \cdot 6 \\
1 \cdot 5 \\
5 \cdot 1\end{array}$ \\
\hline $\begin{array}{l}45 \\
56\end{array}$ & $\begin{array}{l}0 \\
0\end{array}$ & $\begin{array}{l}0 \\
0\end{array}$ & $\begin{array}{l}2 \cdot 9 \\
2 \cdot 6\end{array}$ \\
\hline 60 & 0 & 0 & 1 \\
\hline $\begin{array}{r}64 \\
83 \\
85 \\
87 \\
91 \\
98 \\
100 \\
101 \\
105 \\
75 \\
76\end{array}$ & $\begin{array}{l}0 \\
0 \\
0 \\
0 \\
0 \\
0 \\
0 \\
0 \\
0 \\
0 \\
0\end{array}$ & $\begin{array}{c}0 \\
0 \\
10 \cdot 0 \\
0 \\
0 \\
0 \\
0 \\
0 \\
0 \\
0 \\
0\end{array}$ & $\begin{array}{l}3 \cdot \\
2 \cdot \\
2 \cdot \\
1 \cdot \\
2 \cdot \\
3 \cdot \\
2 \cdot \\
3 \cdot \\
1 \\
2 \cdot \\
3\end{array}$ \\
\hline
\end{tabular}

Treatment

\begin{tabular}{lll} 
After sham-E.C.T. & \\
\hline $\begin{array}{l}\% \text { Avoidance } \\
(60 \text { trials })\end{array}$ & $\begin{array}{l}\% \text { Vocal CR } \\
(60 \text { trials })\end{array}$ & $\begin{array}{l}\text { Escape time } \\
(\mathrm{sec})\end{array}$
\end{tabular}

Restricted

(a) feeding (6-7 days)

(b) sham-E.C.T (5 days)

(c) recovery (5 days)

TABLE II

AVOIDANCE, ESCAPE, AND CONDITIONED VOCAL RESPONSES IN RATS WITH MEDIAL THALAMIC LESIONS BEFORE AND AFTER E.C.T. $(\mathrm{N}=16)$

Rat No.

\begin{tabular}{lccc} 
Rat No. & \multicolumn{3}{l}{ After Thalamic Lesion } \\
\cline { 2 - 4 } $\begin{array}{c}\text { \% Avoidance } \\
\text { (30 trials) }\end{array}$ & $\begin{array}{c}\% \text { Vocal CR } \\
\text { (30 trials) }\end{array}$ & $\begin{array}{l}\text { Escape } \\
\text { (sec) }\end{array}$ \\
\hline 46 & 0 & 0 & $2 \cdot 7$ \\
50 & 0 & 0 & $3 \cdot 0$ \\
58 & 0 & 0 & $2 \cdot 1$ \\
59 & 0 & $6 \cdot 7$ & $2 \cdot 6$ \\
90 & 0 & 0 & $1 \cdot 8$ \\
71 & 0 & 0 & \\
94 & 0 & 0 & $2 \cdot 8$ \\
66 & 0 & & $3 \cdot 4$ \\
80 & 0 & 0 & $2 \cdot 4$ \\
93 & 0 & 0 & $1 \cdot 9$ \\
$60 \mathrm{JB}$ & 0 & $3 \cdot 3$ & $2 \cdot 0$ \\
77 & 0 & 0 & $2 \cdot 2$ \\
37 & 0 & 0 & $2 \cdot 4$ \\
27 & 0 & $6 \cdot 7$ & $2 \cdot 1$ \\
79 & 0 & $6 \cdot 7$ & $2 \cdot 8$ \\
14 & 0 & 0 & $1 \cdot 3$ \\
& 0 & 0 & $2 \cdot 5$ \\
& 0 & &
\end{tabular}

Treatment

responses (range $=21-29$ ). When retested 16 days later, they showed significant retention, receiving an average of 1.5 shocks (range $=1-3$ ) in 30 trials $(P<0.02$; Wilcoxon test). On the final day of testing the average number of shocks received declined to 0.8 (range $=0-2$ ).

The performance of the experimental group was initially very much like that of the control group. The rats received an average of 3.4 shocks in 30

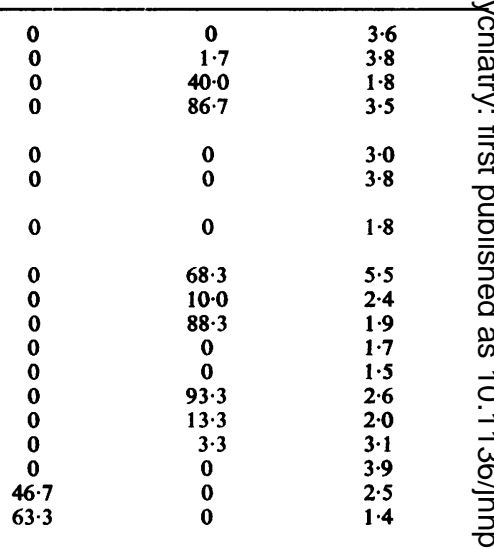

$\begin{array}{lll}\text { After E.C.T. } & & \\ \begin{array}{l}\% \text { Avoidance } \\ (60 \text { trials })\end{array} & \begin{array}{l}\% \text { Vocal CR } \\ (60 \text { trials })\end{array} & \begin{array}{l}\text { Escape time } \\ (\text { sec })\end{array}\end{array}$

(a) Restricted feeding (6-7 days)

(b) E.C.T. (5 days)

(c) Recovery (5 days)

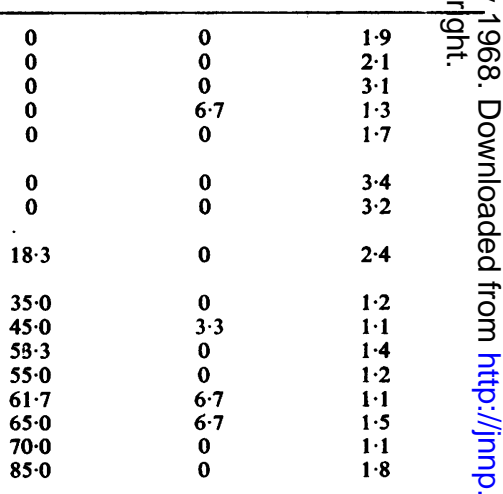

trials (range $=1-7$ ). When retested after the con 8 vulsive treatment, the animals showed no retention of this training, receiving an average of 3.5 shocks in 30 trials (range $=1-6$ ). This is significantly poore? than the retest performance of the control rats $(P<0.005)$. New learning proceeded normally an the next day the animals received 1.5 shock (range 1-3) in 30 trials. This is identical with the initial retest performance of the control animalss 
Thus, the effect of 20 convulsions was to wipe out entirely the retention of a training session which had occurred six days previously.

\section{DISCUSSION}

Electrically induced convulsions improve avoidance performance in rats with large medial thalamic lesions but abolish retention of the same behaviour in normal animals. The hypothesis proposed here is that the first effect, improvement, is due to a reduction in the activity of a somato-motor inhibitory system which is responsible for the freezing behaviour characteristic of a frightened rat. The reduction in motor inhibition increases the capacity of the hypoactive 'response trigger' (damaged by the medial thalamic lesion) to fire off a motor act. Presumably, this effect does not improve performance in normal animals because their ability to initiate an active movement is already optimal in the one-way avoidance situation here used. Therefore, no improvement is possible and other factors determine the level of performance. This is possible because E.C.T. disrupts a variety of cerebral processes in addition to those involved in motor inhibition (Holmberg, 1963). In particular, learning and memory are adversely affected. There appear to be at least two types of effect present: (1) a loss of memory for events occurring immediately before a convulsion (Glickman, 1961), and (2) a long-term generalized deterioration of cerebral function which impairs retention of old habits and acquisition of new ones as well as disrupting performance of instinctive activities such as food hoarding or care of the young (Munn, 1950). Furthermore, E.C.T. may act as a punishment in some circumstances (Hudspeth and Gerbrandt, 1965).

Disturbances of central mechanisms involved in memory are probably responsible for the loss of retention observed in the normal rats of Experiment 2 and may have occurred in the convulsed rats with thalamic lesions as well. Conceivably, the finding that conditioned vocal responding developed slowly in the latter animals is evidence of this. It seems likely that the disinhibiting effect of E.C.T. was great enough to produce an overall improvement in avoidance performance in the medial thalamusdamaged rats despite the handicap of memory impairment. What may be an analogous situation is seen in clinical practice: E.C.T. is effective in relieving depression, but often produces an impairment of memory as an undesirable side-effect.

Conditioned vocal responding was depressed by E.C.T., even though avoidance performance was enhanced. This result is consistent with other evidence suggesting that the neural organization of the two responses is different. Avoidance responding is blocked by medial thalamic damage; vocal responding is less severely affected. Also, septal damage and pre-test exposure to a novel environment improve avoidance responding but have no effect on conditioned vocal responding in rats with medial thalamic lesions (Vanderwolf, 1964, 1966).

The foregoing results make two points which may be of clinical interest. First, it has been demonstrated that E.C.T. can sometimes ameliorate the effects of a large diencephalic lesion. Second, the results may have implications for the surgical treatment of mental disorders. Previous work (Vanderwolf, 1964) has shown that destruction of the septal nuclei reverses the effect of medial thalamic lesions to approximately the same extent that E.C.T. does. Both agents produce recovery of avoidance performance in about half the cases treated. Other instances of parallel effects on behavioural inhibition have been pointed previously (Vanderwolf, 1963). Such evidence suggests that E.C.T. may produce disinhibition by an effect on the limbic system. A mechanism by which this might occur has been suggested by French, Gernandt, and Livingston (1956). Since limbic structures tend to have a low threshold for seizure discharges (Gastaut and Fischer-Williams, 1959) they might be more reliably and thoroughly convulsed than other parts of the brain during E.C.T. and so be more severely affected. The actual mechanism of the resultant depression of function is unknown, but it might conceivably be a combination of anoxia plus intense local neural activity such as has been proposed by McLardy (1963) to account for the finding that 'cell soma pathology' occurs selectively in the hippocampus following convulsions produced by carbon monoxide.

These considerations suggest that further work might lead to the discovery of a neurosurgical procedure which would have a selective and longlasting effect on depression and related states but have fewer undesirable side-effects than E.C.T. Such a procedure might involve intervention in cerebral inhibitory areas which physiological and behavioural research have located in the septal nuclei and the subcallosal, insular, and orbital cortex (Kaada, 1960; McCleary, 1966). The evidence available on the clinical effect of resection of these general areas is scant but it may be significant that removal of orbital cortex has been reported as an effective treatment for depressive states (Knight, 1964).

\section{SUMMARY}

Following extensive medial thalamic damage, rats are unable to avoid an electric shock by running 
away. Subsequent treatment with electro-convulsive shock produces a substantial improvement in such avoidance performance in about half the cases treated. Control rats (not convulsed) usually remain unchanged. In normal rats, convulsive treatment results in a loss of a previously acquired avoidance habit.

It is suggested that convulsive treatment has at least two effects on the neural mechanisms controlling behaviour: (1) a disturbance of somato-motor inhibitory systems, and (2) an impairment of memory. Possible clinical and physiological implications of the findings are discussed.

The author is indebted to Jo-Ann Bentley for assistance in part of the investigation.

\section{REFERENCES}

Cardo, B. (1961). Rapports entre le niveau de vigilance et le conditionnement chez l'animal. J. Physiol. (Paris), 53, Suppl. 4, pp. 1-212.

Carson, R. C. (1957). The effect of electroconvulsive shock on a learned avoidance response. J. comp. physiol. Psychol., 50, 125-129.

Delacour, J., Albe-Fessard, D., and Libouban, S. (1966). Rôle chez le rat de deux noyaux thalamiques dans le conditionnement instrumental. Neuropsychologia, 4, 101-112.

French, J. D., Gernandt, B. E., and Livingston, R. B. (1956). Regional differences in seizure susceptibility in monkey cortex. Arch. Neurol. Psychiat. (Chic.), 75, 260-274.

Gastaut, H., and Fischer-Williams, M. (1959). The physiopathology of epileptic seizures. In Handbook of Physiology, ed. J. Field, Section I. Neurophysiology. Vol. I, pp. 329-363. American Physiolcgical Society, Washington, D.C.

Gellhorn, E. (1946). Is restoration of inhibited conditioned reactions by insulin coma specific for Pavlovian inhibitions? Arch. Neurol. Psychiat. (Chic.), 56, 216-221.

Glickman, S. E. (1961). Perseverative neural processes and consolidation of the memory trace. Psychol. Bull., 58, 218-233.
Heistad, G. T. (1955). An effect of electroconvulsıve shock on a conz ditioned avoidance response. J. comp. physiol. Psychol., 4\$ 482-487.

Holmberg, G. (1963). Biological aspects of electroconvulsive therapo Int. Rev. Neurobiol., 5, 389-412.

Hudspeth, W. J., and Gerbrandt, L. K. (1965). Electroconvulsiy shock: conflict, competition, consolidation, and neuroanatomical functicns. Psychol. Bull., 63, 377-383.

Kaada, B. R. (1960). Cingulate, posterior orbital, anterior insulat and temporal pole cortex. In Handbook of Physiology, ed J. Field. Section I. Neurophysiology. Vol. 2, pp. 1345-1372 American Physiologal Society, Washington, D.C.

_ Rasmussen, E. W., and Kveim, D. (1962). Impaired acquisition of passive avoidance behavior by subcallosal, septal, hypothalamic, and insular lesions in rats. J. comp. physiol. Psychol $55,661-670$.

Knight, G. C. (1964). The orbital cortex as an objective in the surgic treatment of mental illness. The results of 450 cases of opeo operation and the development of the stereotactic approach Brit. J. surg., 51, 114-124.

McCleary, R. A. (1961). Response specificity in the behaviora effects of limbic system lesions in the cat. J. comp. physio? Psychol., 54, 605-613.

(1966). Response-medulating functions of the limbic system: initiation and suppression. Progr. physiol. Psychol., 1, 209-272.

McDonald, D. G. (1S60). Experimental control of fractures produced by electroconvulsive shock. Amer. J. Physiol., 199, 573-574. $\vec{\omega}$

McLardy, T. (1963). Amphetamine and Ammonshorn-sclerosis Nature (Lond.), 198, 900.

Munn, N. L. (1950). Handbook of Psychological Research on the Rat pp. 441-449. Houghton Mifflin, Boston.

Thompson, R. (1963). Thalamic structures critical for retention of an avoidance conditioned response in rats. J. comp. physiol. Psychol., 56, 261-267.

Vanderwolf, C. H. (1962). Medial thalamic functions in volungarg behavior. Canadian J. Psychol., 16, 318-330.

- (1963). Improved shuttle-box performance following electro convulsive shock. J. comp. physiol. Psychol., 56, 983-986. (1964). Effect of combined medial thalamic and septal lesions on active-avoidance behavior. Ibid., 58, 31-37.

- (1966). Warm-up effects in the avoidance performance of with medial thalamic lesions. Anim. Behav., 14, 425-429.

- (1967). Effects of experimental diencephalic damage on hoarding and shock avoidance behavior in the rat. $P h$ Behav., 2, 399-402. 